\title{
PENTINGNYA PELAKSANAAN SASARAN KESELAMATAN PASIEN DALAM KEPERAWATAN
}

\author{
Try Ayu Amanda Pasaribu
}

\author{
tryayuamanda08@gmail.com
}

\section{LATAR BELAKANG}

Perawat adalah seseorang (seorang profesional) yang mempunyai kemampuan, tanggung jawab dan kewenangan melaksanakan pelayanan/ asuhan keperawatan pada berbagai jenjang pelayanan keperawatan. Keperawatan adalah bentuk pelayanan profesional berupa pemenuhan kebutuhan dasar yang diberikan kepada individu yang sehat maupun sakit yang mengalami gangguan fisik, psikis, dan sosial agar dapat mencapai derajat kesehatan yang optimal.

Rumah sakit merupakan layanan jasa yang memiliki peran penting bagi kehidupan masyarakat. Rumah Sakit merupakan tempat dengan sangat kompleks yang terdapat berbagai macam obat, tes dan prosedur, banyak alat dengan teknologinya, berbagai jenis tenaga profesi dan non profesi yang siap memberikan pelayanan pasien 24 jam terus-menerus.

Sasaran keselamatan pasien merupakan syarat untuk diterapkan di semua rumah sakit yang di akreditasi oleh Komisi Akreditasi Rumah Sakit. Sasaran tersebut mengacu kepada Nine Life-Saving Patient Safety Solutions dari WHO Patient Safety. Sasaran keselamatan pasien terdiri atas 6 sasaran, yaitu ketepatan identifikasi dalam peningkatan komunikasi yang efektif, peningkatan keamanan obat yang perlu diwaspadai (high alert), kepastian tepat lokasi, tepat prosedur, dan tepat pasien operasi, pengurangan risiko infeksi terkait pelayanan kesehatan, dan pengurangan resiko jatuh.

Keselamatan pasien adalah prinsip dasar dalam pelayanan kesehatan. Menurut Depkes RI (2008) Keselamatan Pasien (Patient Safety) rumah sakit adalah suatu sistem di mana rumah sakit membuat asuhan pasien lebih aman. Salah satu tujuan keselamatan pasien yaitu menurunnya KTD yang merupakan bagian dari insiden keselamatan pasien. Untuk mencapai tujuan tersebut, maka disusun lah sasaran keselamatan pasien yang bertujuan mendorong perbaikan spesifik dalam keselamatan pasien. Sasaran menyoroti bagian-bagian yang bermasalah dalam pelayanan kesehatan dan menjelaskan bukti serta solusi dari konsensus 
berbasis bukti dan keahlian atas permasalahan yang ada. Keselamatan (safety) telah menjadi isu global termasuk juga untuk rumah sakit. Oleh karena itu, keselamatan pasien merupakan prioritas utama untuk dilaksanakan dan hal tersebut terkait dengan terjadinya Insiden Keselamatan Pasien (IKP) di rumah sakit.

\section{METODE}

Metode yang digunakan pada kajian ini adalah dengan menganalisis dari berbagai sumber bacaan. Referensi yang saya ambil dari jurnal online,skripsi dan tesis dengan pengerjaannya dengan cara membandingkan artikel satu dengan artikel yang lain.

Metode yang digunakan pengkajian ini dengan mengumpulkan informasi dari berbagai referensi termasuk didalamnya hasil-hasil penelitian.

\section{HASIL}

Hasil dari pengkajian ini Sasaran Keselamatan Pasien merupakan suatu bagian dari Standar Akreditasi Rumah Sakit yang harus dapat diterapkan di rumah sakit yang berguna dalam meningkatkan pelayanan kesehatan yang berkualitas. Pengetahuan tenaga kesehatan dalam Sasaran Keselamatan Pasien terdiri dari ketepatan identifikasi pasien, peningkatan komunikasi yang efektif, peningkatan keamanan obat yang perlu diwaspadai kepastian tepat lokasi, tepat prosedur, dan tepat pasien operasi, pengurangan resiko infeksi terkait pelayanan kesehatan, pengurangan risiko pasien jatuh. Rumah sakit merupakan salah satu tempat yang memberikan pelayanan kesehatan pada pasien, dengan berbagai macam jenis tenaga kesehatan di antaranya adalah perawat dan dokter. Tenaga kesehatan yang bekerja di rumah sakit bertanggung jawab dalam meningkatkan mutu pelayanan kesehatan dalam pengelolaan manajemen resiko keselamatan pasien di rumah sakit. Pada saat ini setiap rumah sakit diwajibkan untuk meningkatkan mutu pelayanan kesehatan yang salah satunya adalah melalui sasaran keselamatan pasien.

Keselamatan pasien di Rumah Sakit (KPRS) adalah sistem pelayanan dalam suatu rumah sakit yang memberikan asuhan pasien menjadi lebih aman, termasuk didalamnya mengukur resiko, identifikasi dan pengelolaan resiko terhadap pasien analisa insiden, kemampuan untuk belajar dan menindaklanjuti insiden serta menerapkan solusi untuk mengurangi resiko.

World Health Organization (WHO) menyatakan keselamatan pasien merupakan masalah kesehatan masyarakat global yang serius. Kesalahan medis dapat disebabkan oleh 
faktor sistem dan faktor manusia. Insiden keselamatan pasien yang merugikan adalah terkait dengan prosedur bedah, kesalahan pengobatan dan kesehatan infeksi terkait perawatan.

Keselamatan menjadi isu global dan terangkum dalam lima isu penting yang terkait di rumah sakit yaitu keselamatan pasien, keselamatan pekerja atau petugas kesehatan, keselamatan bangunan dan peralatan di rumah sakit, keselamatan lingkungan dan keselamatan bisnis rumah sakit yang terkait dengan kelangsungan hidup rumah sakit. Kementerian Kesehatan Republik Indonesia telah mengeluarkan Peraturan Menteri Kesehatan No. 11 Tahun 2017 tentang Keselamatan Pasien di Rumah sakit. Peraturan ini menjadi tonggak utama operasionalisasi keselamatan pasien di rumah sakit seluruh Indonesia. Banyak rumah sakit di Indonesia yang telah berupaya membangun dan mengembangkan keselamatan pasien, namun upaya tersebut dilaksanakan berdasarkan pemahaman manajemen terhadap keselamatan pasien. Peraturan menteri ini memberikan panduan bagi manajemen Rumah Sakit agar dapat menjalankan spirit keselamatan pasien secara utuh. Keselamatan pasien adalah suatu sistem yang membuat asuhan pasien lebih aman, meliputi assessment risiko, Identifikasi dan pengelolaan risiko pasien, pelaporan dan analisis insiden, kemampuan belajar dari insiden dan tindak lanjutnya, serta implementasi solusi untuk meminimalkan timbulnya risiko dan mencegah terjadinya cedera yang disebabkan oleh kesalahan akibat melaksanakan suatu tindakan atau tidak mengalami tindakan yang seharusnya diambil.

\section{PEMBAHASAN}

Sasaran Keselamatan Pasien adalah mendorong perbaikan spesifik dalam keselamatan pasien. Sasaran menyoroti bagian-bagian yang bermasalah dalam pelayanan kesehatan dan menjelaskan bukti serta solusi dari konsensus berbasis bukti dan keahlian atas permasalahan ini. Diakui bahwa desain sistem yang baik secara intrinsik adalah untuk memberikan pelayanan kesehatan yang aman dan bermutu tinggi, sedapat mungkin sasaran secara umum difokuskan pada solusi-solusi yang menyeluruh. Enam Sasaran Keselamatan Pasien adalah tercapainya hal-hal berikut :

1. Sasaran I : Ketepatan identifikasi pasien

2. Sasaran II : Peningkatan komunikasi yang efektif

3. Sasaran III : Peningkatan keamanan obat yang perlu diwaspadai (High-Alert)

4. Sasaran IV : Kepastian tepat lokasi, tepat prosedur, tepat pasien operasi

5. Sasaran V : Pengurangan risiko infeksi terkait pelayanan kesehatan

6. Sasaran VI : Pengurangan resiko pasien jatuh 
Pelaksanaan 6 sasaran keselamatan pasien oleh perawat di Rumah Sakit berada dalam kategori baik. Diharapkan pihak rumah sakit dapat melengkapi standar prosedur operasional mengenai komunikasi efektif saat melaporkan dan menerima instruksi dari dokter, adanya \& label untuk keamanan obat, dan peningkatan supervisi agar pelaksanaan teknik aseptik menjadi lebih baik.

Keselamatan pasien merupakan prinsip dasar perawatan kesehatan di lembaga kesehatan yang terus membutuhkan peningkatan kualitas. Faktor penting dalam memastikan keselamatan pasien adalah kualitas keperawatan. Keselamatan pasien adalah suatu sistem yang membuat asuhan pasien lebih aman, meliputi asesmen risiko, Identifikasi dan pengelolaan risiko pasien, pelaporan dan analisis insiden, kemampuan belajar dari insiden dan tindak lanjutnya, serta implementasi solusi untuk meminimalkan timbulnya risiko dan mencegah terjadinya cedera yang disebabkan oleh kesalahan akibat melaksanakan suatu tindakan atau tidak mengambil tindakan yang seharusnya diambil. Berpedoman pada sasaran Keselamatan Pasien pada Standar Nasional Akreditasi Rumah Sakit tahun 2017 menyebutkan bahwa identifikasi pasien penting untuk mengidentifikasi pasien yang akan mendapatkan pelayanan atau pengobatan agar tidak terjadi kekeliruan. Perawat harus menyadari perannya sebagai keselamatan pasien di rumah sakit sehingga harus dapat berpartisipasi aktif dalam mewujudkan dengan baik. Pengetahuan perawat tentang patient safety sangat berpengaruh terhadap kinerja perawat itu sendiri dalam penerapan dan pelaksanaan tindakan terhadap patient safety di rumah sakit. Dalam lingkup patient safety pengetahuan perawat merupakan hal yang berhubungan dengan komitmen yang sangat diperlukan dalam upaya membangun budaya keselamatan pasien. Keselamatan pasien di rumah sakit menjadi isu penting karena banyaknya kasus medical error yang terjadi di berbagai negara.

Seorang perawat dalam memberikan asuhan keperawatan harus memiliki pengetahuan yang benar, keterampilan, dan sikap untuk menangani kompleksitas perawatan kesehatan. Tanpa pengetahuan yang memadai, tenaga kesehatan termasuk perawat tidak bisa menerapkan dan mempertahankan budaya keselamatan pasien. Dengan demikian dapat dijelaskan bahwa semakin tinggi pengetahuan perawat tentang penerapan keselamatan pasien, diharapkan semakin tinggi pula perawat dalam memahami pentingnya penerapan keselamatan pasien yang diberikan kepada pasien dalam pelayanan keperawatan. Begitupun sebaliknya apabila pengetahuan pemberi asuhan keperawatan kurang dalam menerapkan dan mempertahankan budaya keselamatan pasien akan berdampak pada kesalahan identifikasi pasien yang nantinya bisa berakibat fatal jika pasien menerima prosedur medis yang tidak sesuai dengan kondisi pasien seperti salah pemberian obat, salah pengambilan darah bahkan salah tindakan medis. 
Solusi tercapainya patient safety di lingkungan rumah sakit, langkah pertama yang perlu dilakukan adalah melakukan sosialisasi dengan berbagai metode dan media di antaranya melakukan seminar, workshop untuk perawat dan petugas kesehatan lainnya melalui poster dan leaflet, monitoring dan evaluasi penerapan SOP secara berkala oleh komite keperawatan juga perlu dilakukan untuk meningkatkan kepatuhan pelaksanaan identifikasi pasien sehingga dapat menurunkan angka insiden keselamatan pasien, selain itu dalam pelaksanaannya diperlukan supervisi sebagai alat evaluasi dan perbaikan. Keselamatan pasien merupakan suatu variabel untuk mengukur dan mengevaluasi kualitas pelayanan kesehatan yang berdampak terhadap pelayanan kesehatan.

\section{- Tujuan Program Keselamatan Pasien}

1. Terciptanya budaya keselamatan pasien di rumah sakit

2. Meningkatkan akuntabilitas Rumah Sakit terhadap pasien dan masyarakat

3. Menurunnya kejadian yang tidak diharapkan di rumah sakit

4. terlaksananya program-program pencegahan sehingga tidak terjadi pengulangan kejadian tidak diharapka

Insiden Keselamatan Pasien adalah setiap kejadian yang tidak disengaja dan kondisi yang mengakibatkan atau berpotensi mengakibatkan cedera yang dapat dicegah pada pasien. Beberapa insiden Keselamatan Pasien :

1. Kejadian Tidak Diharapkan (KTD) KTD adalah insiden yang mengakibatkan cedera pada pasien

2. Kejadian Nyaris Cedera (KNC)

KNC adalah terjadinya insiden yang belum sampai terpapar ke pasien

3. Kejadian Tidak Cedera (KTC)

KTC adalah insiden yang sudah terpapar ke pasien, tetapi tidak timbul cedera

4. Kejadian Potensial Cedera

KPC adalah kondisi yang sangat potensial untuk menimbulkan cedera, tetapi belum terjadi insiden

5. Kejadian Sentinel

Kejadian sentinel adalah suatu KTD yang mengakibatkan kematian atau cedera yang serius (Komite Keselamatan Pasien Rumah Sakit)

- Tujuh Langkah Menuju Keselamatan Pasien

1) Membangun kesadaran nilai keselamatan pasien

2) Memimpin dan mendukung staf 
3) Mengintegrasikan aktivitas pengelolaan risiko

4) Mengembangkan sistem pelaporan

5) Melibatkan dan berkomunikasi dengan pasien

6) belajar dan berbagi pengalaman tentang keselamatan pasien

7) Mencegah cedera melalui implementasi sistem keselamatan pasien

Rumah Sakit merupakan layanan jasa yang memiliki peran penting bagi kehidupan masyarakat. Rumah sakit merupakan tempat yang sangat kompleks yang terdapat berbagai macam obat, tes dan prosedur, banyak alat dengan teknologinya, berbagai jenis tenaga profesi dan non profesi yang siap memberikan pelayanan pasien 24 jam terus menerus. Keberagaman dan kerutinan pelayanan tersebut apabila tidak dikelola dengan baik dapat menimbulkan peluang untuk terjadinya kesalahan pelayanan yang dapat berakibat terhadap keselamatan pasien. Dalam Permenkes RI No. 1691/MENKES/PER/VIII/2011 tentang Keselamatan Pasien Rumah Sakit, dikatakan Insiden Keselamatan Pasien yang selanjutnya disebut insiden adalah setiap kejadian yang tidak disengaja dan kondisi yang mengakibatkan atau berpotensi mengakibatkan cedera yang dapat dicegah pada pasien, terdiri dari Kejadian Tidak Diharapkan (KTD), Kejadian Nyaris Cedera (KTC) dan Kejadian Potensial Cedera (KPC). Salah satu tujuan keselamatan pasien yaitu menurunnya KTD yang merupakan bagian dari insiden keselamatan pasien. Untuk mencapai tujuan tersebut, maka disusunlah Sasaran Keselamatan Pasien yang bertujuan mendorong perbaikan spesifik dalam keselamatan pasien. Sasaran menyoroti bagian-bagian yang bermasalah dalam pelayanan kesehatan dan menjelaskan bukti serta solusi dari konsensus berbasis bukti dan kalian atas permasalahan yang ada. Penyusunan sasaran ini mengacu kepada Nine Life-Saving Patient Safety Solutions dari WHO Patient Safety yang digunakan juga oleh Komite Keselamatan Pasien Rumah Sakit PERSI (KKPRS PERSI), dan dari Joint Commission International (JCI). Oleh karena itu, jika Rumah Sakit ingin menurunkan kejadian insiden keselamatan pasien maka Rumah Sakit harus menerapkan budaya keselamatan pasien.

Salah satu masalah umum yang terjadi dalam pemberian pelayanan di bidang kesehatan adalah masalah yang berkaitan dengan keselamatan pasien. Perawat sebagai ujung tombak pemberi Pelayanan Kesehatan merupakan hal yang penting untuk dikaji dalam rangka mempertahankan dan meningkatkan mutu pelayanan kesehatan. Kinerja yang baik merupakan jembatan dalam menjawab kualitas pelayanan kesehatan yang diberikan terhadap pasien baik yang sakit maupun yang sehat. Perawat harus sadar akan perannya sehingga dapat secara aktif ikut berpartisipasi untuk mewujudkan keselamatan pasien. Hal ini juga tidak akan mencapai 
optimal jika hanya dengan kerja keras dari perawat saja, namun didukung dengan sarana prasarana, manajemen rumah sakit dan tenaga kesehatan lainnya.

Joint Commission International (JCI) membagi beberapa sasaran keselamatan pasien yaitu komponen identifikasi pasien, komponen penggunaan komunikasi efektif, komponen pemakaian obat dengan kewaspadaan tinggi, komponen ketepatan lokasi operasi, prosedur dan pasien yang akan dibedah, komponen mengurangi risiko terinfeksi, komponen menilai resiko pasien jatuh.

\section{PENUTUP}

Isu keselamatan pasien melahirkan paradigma baru tentang mutu pelayanan. Mutu pelayanan yang baik saja tidak cukup berarti bagi pasien tanpa memperhatikan bagaimana derajat untuk resiko dan keselamatan yang diterima oleh pasien. Keperawatan adalah meningkatkan respon adaptasi yang berhubungan dengan empat model respon adaptasi. Insiden keselamatan pasien dapat dikurangi atau dicegah kejadiannya dengan mengetahui faktor yang berkontribusi terhadap terjadi insiden keselamatan pasien. Penerapan program keselamatan pasien lebih efektif dibandingkan dengan faktor-faktor lain dalam menurunkan angka kejadian insiden keselamatan pasien. Keselamatan pasien merupakan tanggung jawab semua pihak yang berkaitan dengan pemberi pelayanan kesehatan. Salah satu upaya untuk meminimalkan insiden atau kejadian patient safety, keperawatan sebagai pelayanan profesional yang merupakan ujung tombak pelayanan kepada pasien harus bertindak dengan didasari oleh ilmu pengetahuan termasuk pengetahuan tentang patient safety, sehingga Asuhan Keperawatan yang diberikan berkualitas dan bermanfaat dalam mencegah Insiden Kejadian Tidak di Diharapkan (KTD).

\section{REFERENSI}

1) Atrium,Diah, Salbiah, Murniati Manik.2015. Pengetahuan Tenaga Kesehatan Dalam Sasaran Keselamatan Pasien di Rumah Sakit Sumatera Utara. Idea Nursing Journal. Vol: VI(2).1-6.

2) Bawelle SC, Sinolungan JS, Hamel R.2013. Hubungan Pengetahuan dan Sikap Perawat dengan Pelaksanaan Keselamatan Pasien (patient safety) di Ruang Rawat Inap RSUD Liun Kendage Tahuna. Jurnal Keperawatan, 1(1).

3) Darliana,D.2016. Hubungan Pengetahuan Perawat Dengan Upaya Penerapan Patient Safety di Ruang Rawat Inap Rumah Sakit Umum Daerah DR.Zainoel Abidin Banda Aceh. Idea Nursing Journal.VII(1).61-69. 
4) Harus, Bernadeta Dece,dkk.2015. Pengetahuan Perawat tentang Keselamatan Pasien Dengan Pelaksanaan Prosedur Keselamatan Pasien Rumah Sakit (KPRS) Di Rumah Sakit Panti Waluya Sawahan Malang. Jurnal CARE. Vol: 3(1).25-32.

5) Insani, Tria Harsiwi Nurul, Sri Sundari.2018. Analisis Pelaksanaan Keselamatan Pasien Oleh Perawat. Journal of Health Studies. Vol: 2(1).84-95.

6) Juniarti, Nanda Hani, Ahmad Ahid Mudayana.2018. Penerapan Standar Keselamatan Pasien di Rumah Sakit Umum Daerah Provinsi Nusa Tenggara Barat. Jurnal Kesehatan Poltekkes Ternate. Vol: 11(2).93-108.

7) Keles, Angelia W, G.D Kandou, Ch.R.Tilaar.2015. Analisis Pelaksanaan Standar Sasaran Keselamatan Pasien di Unit Gawat Darurat RSUD Dr. Sam Ratulangi Tondano Sesuai dengan Akreditasi Rumah Sakit Versi 2012. JIKMU.Vol: 5(2).250-259.

8) Myers,S.2012. Patient Safety and Hospital Accreditation : a Model For Ensuring Success. New York: Springer Publishing Company.

9) Najihah.2018. Budaya Keselamatan Pasien dan Insiden Keselamatan Pasien di Rumah Sakit: Literatur review. Journal of Islami Nursing. Vol: 3(2).1-8.

10) Neri, Reno Afriza,dkk.2018. Analisis Pelaksanaan Sasaran Keselamatan Pasien di Rawat Inap Rumah Sakit Umum Daerah Padang Pariaman. Jurnal Kesehatan Andalas. Vol: $7(4) .48-55$.

11) Nursalam.2015. Manajemen Keperawatan: Aplikasi Dalam Praktik Keperawatan Profesional Edisi 5. Jakarta: Salemba Medika.

12) Rasam, Rianayanti Asmira.2017. Analisis Tatakelola Sasaran Keselamatan Pasien Pada Alur Pelayanan Penyakit Sepsis di Rumah Sakit Tebet 2015. Jurnal Administrasi Rumah Sakit. Vol: 3(2).100-113.

13) Rofina Lusia Jawa ITO.2019. Hubungan Tingkat Pengetahuan Perawat Tentang Identifikasi dalam Patient Safety dengan Pelaksanaannya di Rumah Rawat Inap RSUD SK.Lerik Kupang. Skripsi. Program Studi Ilmu Keperawatan Sekolah Tinggi Ilmu Kesehatan Hang Tuah Surabaya.

14) Simamora, R.H.(2018). Buku Ajar Keselamatan Pasien Melalui Timbang Terima Pasien berbasis Komunikasi Efektif: SBAR. Medan: USUpress.

15) Simamora, R.H.(2020). Learning of Patient Identification in Patient Safety Programs Through Clinical Preceptor Models. Medico Legal Update, 20(3),553-556.

16) Sundoro,Totok, Elsye Maria Rosa, Irma Rosdiana.2016. Evaluasi Pelaksanaan Sasaran Keselamatan Pasien sesuai Akreditasi Rumah Sakit Versi 2012 di Rumah Sakit Khusus 
Ibu dan Anak PKU Muhammadiyah Kotagede Yogyakarta. Jurnal Medicoeticolegal dan Manajemen Rumah Sakit. Vol: 5(1).40-48. 